\title{
Predicting Survival in Oldest Old People
}

\author{
Diana G. Taekema, MD, PhD, ${ }^{a, b}$ J. Gussekloo, MD, PhD, ${ }^{c}$ Rudi G. J. Westendorp, MD, PhD, ${ }^{a, d}$ \\ Anton J. M. de Craen, PhD, ${ }^{\text {a,d }}$ Andrea B. Maier, MD, PhD ${ }^{\mathrm{a}, \mathrm{d}}$
}

${ }^{a}$ Department of Gerontology and Geriatrics, Leiden University Medical Center, Leiden, the Netherlands; ${ }^{b}$ Department of Geriatrics, Rijnstate Hospital, Arnhem, the Netherlands; ${ }^{c}$ Department of Public Health and Primary Care, Leiden University Medical Center, Leiden, the Netherlands; ${ }^{d}$ Netherlands Consortium for Healthy Aging, Leiden University Medical Center, Leiden, the Netherlands.

\begin{abstract}
OBJECTIVE: Measures of physical performance are regarded as useful objective clinical tools to estimate survival in elderly people. However, oldest old people, aged 85 years or more, are underrepresented in earlier studies and frequently unable to perform functional tests. We studied the association of gait speed and survival in a cohort of oldest old people and the association of Instrumental Activities of Daily Living by questionnaire and survival as an alternative prognostic marker of survival.

METHODS: The Leiden 85-plus Study was used, a prospective population-based study with a follow-up period of 12 years. The study comprised 599 participants all aged 85 years at baseline. Survival rate was the measurement.

RESULTS: At age 85 years, 73 participants (12.2\%) did not perform the walking test. Gait speed faster than 0.8 $\mathrm{m} / \mathrm{s}$ was present in only 48 participants $(9 \%)$, and gait speed faster than $1.0 \mathrm{~m} / \mathrm{s}$ was present in 10 participants $(1.9 \%)$. Risk for all-cause mortality was higher in participants with slow gait speed after 2 and 12 years of follow-up (hazard ratio [HR], 2.66; 95\% confidence interval [CI], 1.49-4.75; $P<.001$; and HR, 2.04; 95\% CI, 1.61-2.59; $P=.100$, respectively). Significance was lost after adjustment for common confounders. Poor Instrumental Activities of Daily Living ability was associated with an increased risk of mortality after 2 and 12 years of follow-up (HR, 6.11; 95\% CI, 3.44-10.87; $P<.001$; and HR, 2.75; 95\% CI, 2.22-3.40; $P<.001$, respectively). Adjustment for possible confounders attenuated the relation but remained significant.

CONCLUSIONS: The cutoff points for gait speed in oldest old people need to be reevaluated. In oldest old people aged 85 years, slow gait speed $(\leq 0.40 \mathrm{~m} / \mathrm{s}$ in women and $\leq 0.45 \mathrm{~m} / \mathrm{s}$ in men) and Instrumental Activities of Daily Living disability are both predictors of survival. Assessment of Instrumental Activities of Daily Living could be a better tool for short- and long-term prognostication of survival in oldest old people.

(C) 2012 Elsevier Inc. All rights reserved. • The American Journal of Medicine (2012) 125, 1188-1194
\end{abstract}

KEYWORDS: Disability; Epidemiology; Gait speed; Instrumental Activities of Daily Living; Oldest old people; Survival

SEE RELATED EDITORIAL p. 1149

Measuring physical performance in elderly patients is regarded as a useful tool in clinical practice to predict future functional outcome and survival. Population-based longitudinal studies in elderly people have shown an association between poor lower-extremity function and disability, hos-

Funding: The work was supported by the Program Translational Research of the Netherlands organization for health research and development, the Leiden University Fund, and an unrestricted grant from the Netherlands Organization of Scientific Research (ZonMw), the Ministry of Health, Welfare, and Sports, the Netherlands Genomics Initiative/Netherlands Organization for scientific research (05040202 and 050-060-810 Netherlands Consortium for Healthy Aging), and the seventh framework program MYOAGE (HEALTH-2007-2.4.5-10). pitalization, and survival in subjects with ages ranging from 65 to more than 80 years. $^{1,2}$

Walking is one of the most important activities that people perform on a daily basis. A significant association between gait speed and survival in elderly people with a

Conflict of Interest: None of the authors have any conflicts of interest associated with the work presented in this manuscript.

Authorship: All authors had access to the data and played a role in writing this manuscript.

Requests for reprints should be addressed to Diana G. Taekema, MD, Department of Gerontology and Geriatrics, C2-R-133, Leiden University Medical Center, PO Box 9600, 2300 RC Leiden, the Netherlands.

E-mail address: d.g.taekema@lumc.nl 
mean age of 73.5 (standard deviation, 5.9) years was recently reported. ${ }^{3}$ The suggested critical cutoff point in earlier reports are $0.8 \mathrm{~m} / \mathrm{s}$ for increased risk of adverse health outcome and $1.0 \mathrm{~m} / \mathrm{s}$ for increased risk of mortality. ${ }^{2,3}$ Gait speed is a parameter of muscle function, but it also depends on other important factors, such as cognition, neural control, joint function, and cardiovascular fitness. ${ }^{4}$ Furthermore, declining energy availability due to impaired energy homeostasis lowers the fatigue threshold in older people and thus contributes to declining physical performance. ${ }^{5}$

In geriatric medicine, a considerable number of patients are aged over 75 years, with approximately $20 \%$ aged over 85 years. ${ }^{6}$ Demographics will change dramatically in the years to come, and in 2050 oldest old adults, aged over 85 years, will account for one fifth of all older persons globally. ${ }^{7}$ Oldest old people are relatively underrepresented in earlier studies testing the relation between gait speed and survival, and some studies did not adjust for cognitive impairment, depressive symptoms, and physical activity level. ${ }^{1-3}$ In a sample of 335 people aged 80 years and older, Cesari et $\mathrm{al}^{8}$ showed that gait speed was not predictive of mortality after adjustment for common confounders. Furthermore, the inability of oldest old people to perform the functional test complicates assessment and calls for an alternative measure of physical performance, such as self-reported ability to perform activities of daily living. Several studies have shown that selfreport measures of physical function are correlated with performance-based measures in elderly subjects aged over 75 years. ${ }^{9-11}$ Measuring gait speed might not always be feasible in every clinical setting. Therefore, we studied the association of both gait speed and Instrumental Activities of Daily Living with survival in a comprehensive longitudinal population-based cohort of oldest old people.

\section{MATERIALS AND METHODS}

\section{Subject Characteristics}

The Leiden 85-plus Study is a population-based prospective follow-up study of inhabitants of the city of Leiden, the Netherlands. Enrollment took place between 1997 and 1999. All inhabitants who reached the age of 85 years during the enrollment period were eligible to participate. ${ }^{12}$ There were no selection criteria. A total of 599 persons participated, $87 \%$ of all eligible inhabitants. Details are provided in a previous publication. ${ }^{13}$ In short, a research nurse visited participants at their place of residence. During these visits, interviews and performance tests were conducted, blood samples were collected, and an electrocardio- gram was recorded. The medical history was obtained from the general practitioner or nursing home physician. Follow-up visits were performed annually. The study was approved by the Medical Ethical Committee of the Leiden University Medical Center. All subjects gave informed consent. For persons with severe cognitive impairment, informed consent was given by a guardian.

\section{Gait Speed}

Gait speed was assessed at the participant's home with a 6-m walking test. The course was denoted by a tape measurement. Participants were requested to walk as quickly as possible from a standing start position, and total time was measured by stopwatch. Use of a walking aid was allowed. Gait speed was calculated using distance in meters and time in seconds (meters per second $[\mathrm{m} / \mathrm{s}]$ ) for 526 participants $(87.8 \%)$. Participants unable to perform the $6-\mathrm{m}$ walking test were excluded from the analysis.

\section{Functional Ability in Instrumental Activities of Daily Living}

Ability to complete daily activities was measured by selfreport at age 85 years by the Groningen Activity Restriction Scale and assesses competence instead of actual performance by phrasing questions as "Can you ...."14 It assesses competence in 9 instrumental abilities, that is doing light housework, doing heavy cleaning, washing and ironing clothes, cleaning and making the bed, preparing a hot meal, climbing the stairs, getting around outdoors, shopping, and attending to feet and toenails. Competence is categorized on a 4-point scale ranging from "Yes, I can do it fully independently without any difficulty" to "No, I cannot do it all, I need complete help." A summed score was calculated for Instrumental Activities of Daily Living ranging from 9 (indicating ability) to performing all activities without assistance or undue effort) to 36 (indicating disability).

\section{Potential Confounders}

The 15-item Geriatric Depression Scale was used to measure depressive symptoms. ${ }^{15}$ Global cognitive performance was assessed with the Mini Mental State Examination. ${ }^{16}$ Four items from the Time Spending Pattern questionnaire were selected to constitute physical exercise above selfreported routine daily physical activity. ${ }^{17}$ They were walking for fun, cycling for fun, exercising alone or in groups or other physical activity, and working in the garden. Each item was scored from 1 (no activity) to 4 (daily activity), and their sum score made up a Physical Activity Score. Other variables were as selected in accordance with the 
study by Studenski et $\mathrm{al}^{3}{ }^{3}$ and included smoking history (current, past, never) and self-reported health (good vs poor). Body mass index was calculated as weight in kilograms divided by height in meters squared. Systolic blood pressure was measured with a mercury sphygmomanometer. Chronic diseases included cardiovascular disease and hypertension, diabetes mellitus, obstructive pulmonary disease, malignancy, Parkinson's disease, and arthritis or osteoarthrosis, which were identified from general practitioner and pharmacists' records, electrocardiogram, and blood sample analysis. ${ }^{13}$

\section{Follow-up}

All subjects were followed up for survival to January 2010 . Dates of deaths were obtained from the Dutch Civic Registry.

\section{Statistical Analysis}

We used a chi-square test to compare normally distributed variables and a Mann-Whitney $U$ test to compare nonnormally distributed variables. Gender-specific tertiles for gait speed and Instrumental Activities of Daily Living were calculated. The use of tertiles was prespecified for reasons of statistical power and visualization of the results. KaplanMeier curves were applied to display survival in tertiles of baseline gait speed and Instrumental Activities of Daily Living. Analysis for survival was assessed using Cox regression analyses. Hazard ratios (HRs) for mortality were first calculated in the crude analysis (model 1). Subsequent models were adjusted for summed chronic diseases, systolic blood pressure, smoking status, and self-reported health; Physical Activity Score and walking aid use (model 2); 15-item Geriatric Depression Scale and Mini Mental State Examination score (model 3); Instrumental Activities of Daily Living for gait speed analysis (model 4); and gait speed for Instrumental Activities of Daily Living analysis (model 5). Finally, the model was adjusted for all included factors (model 6). The analyses were repeated including only independently living community-dwelling participants $(n=329)$. From a clinical perspective, assessment of mortality risk over a shorter timeframe might be more useful with regard to decision-making and end-of-life care planning. For this reason, the analysis was repeated to assess 1and 2-year survival. All statistical analyses were performed using SPSS for Windows (SPSS Inc, Chicago, Ill), version 17. $P$ values less than .05 were considered to be significant.

\section{RESULTS}

After a follow-up period of 12.2 years (median, 5.8 years; interquartile range, 3.1-8.9 years), 542 participants (90.2\%) died. At the age of 85 years, mean (standard deviation) gait speed was $0.52(0.2) \mathrm{m} / \mathrm{s}$ for the participants who were able to perform the walking test. Figure 1 presents a histogram of the distribution of the gait speed measurement. Gait speed faster than $0.8 \mathrm{~m} / \mathrm{s}$ was present in $48(9 \%)$ of these able participants, and gait speed faster than $1.0 \mathrm{~m} / \mathrm{s}$ was

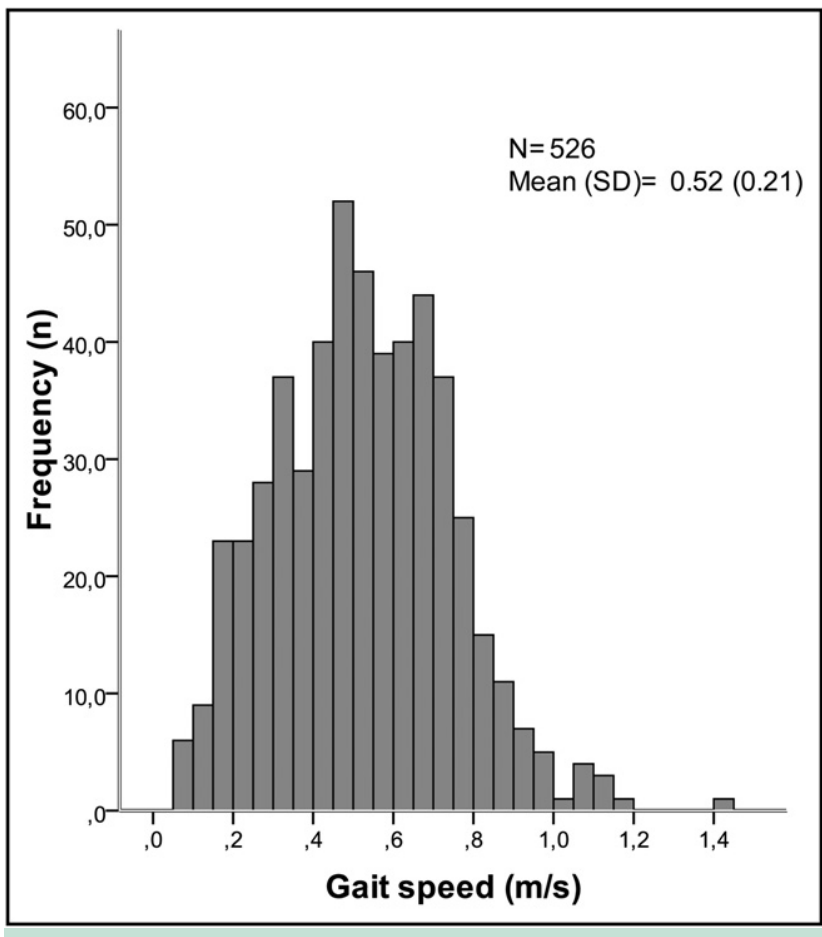

Figure 1 Histogram of gait speed $(\mathrm{m} / \mathrm{s})$ measurement in participants able to complete the walking test $(n=526)$. $\mathrm{SD}=$ standard deviation.

present in $10(1.9 \%)$ of these able participants. Seventythree participants $(12.2 \%)$ did not perform the walking test because of physical limitations $(n=62,10.4 \%)$, severe cognitive impairment $(n=5,0.8 \%)$, and refusal $(n=6,1 \%)$. The characteristics of the participants able to perform the walking test and the participants who did not perform the test are shown in Table 1. The participants who did not perform the walking test were more likely to live institutionalized, were more dependent in Activities of Daily Living, and had worse cognitive function.

Figure 2A and $\mathbf{B}$ show the Kaplan-Meier cumulative survival curves for all-cause mortality according to genderspecific tertiles of gait speed and ability to perform the walking test, respectively. After 5 years of follow-up, $44.8 \%(\mathrm{n}=78)$ of the 174 participants with the slowest walking speed $(\leq 0.40 \mathrm{~m} / \mathrm{s}$ in women and $\leq 0.45 \mathrm{~m} / \mathrm{s}$ in men) survived (Figure 2A). In the fastest gait speed tertile $(\geq 0.59 \mathrm{~m} / \mathrm{s}$ in women and $\geq 0.69 \mathrm{~m} / \mathrm{s}$ in men), $72.1 \%$ $(n=127)$ of the 176 participants survived after this follow-up period. All-cause mortality was significantly higher in participants who did not perform the walking test compared with those who completed the walking test (HR, 2.51; 95\% confidence interval $[\mathrm{CI}], 1.96-3.23 ; P<.001$, unadjusted). After 5 years of follow-up, $17.8 \%(n=13)$ of the 73 participants unable to perform the walking test at baseline survived (Figure 2B). Table 2 (left) presents the HR for all-cause mortality stratified by tertiles of gait speed at age 85 years. The fastest gait speed tertile was used as the reference group $(\geq 0.59 \mathrm{~m} / \mathrm{s}$ in women and $\geq 0.69 \mathrm{~m} / \mathrm{s}$ in 
Table 1 Characteristics of Participants at 85 Years Stratified by Ability to Perform Walking Test

\begin{tabular}{|c|c|c|c|c|}
\hline & \multirow[b]{2}{*}{$\begin{array}{l}\text { All } \\
N=599\end{array}$} & \multicolumn{2}{|c|}{ Ability to Perform Walking Test } & \multirow[b]{2}{*}{$P$ Value* } \\
\hline & & $\begin{array}{l}\text { Yes } \\
N=526\end{array}$ & $\begin{array}{l}\text { No } \\
\mathrm{N}=73\end{array}$ & \\
\hline Men (No., \%) & $203(33.9)$ & $189(35.9)$ & $14(19.2)$ & .005 \\
\hline Living arrangements (No., \%) & & & & $<.001$ \\
\hline Independently living & $329(54.9)$ & $314(59.7)$ & $15(20.6)$ & \\
\hline \multicolumn{5}{|l|}{ Health characteristics } \\
\hline BMI (mean, SD) & $27.2(4.5)$ & $27.2(4.4)$ & $26.9(4.8)$ & .713 \\
\hline Systolic blood pressure (mm Hg, mean, SD) & $155.1(18.7)$ & $156.3(17.9)$ & $145.5(21.4)$ & $<.001$ \\
\hline Smoking (No., \%) & $96(16.0)$ & $84(16.0)$ & $12(4.8)$ & .919 \\
\hline Geriatric Depression Scale (points, median, IQR) & $2(1-3)$ & $2(1-3)$ & $3(2-5)$ & .001 \\
\hline Diabetes mellitus & $96(16.1)$ & $81(15.4)$ & $15(21.1)$ & .146 \\
\hline Obstructive pulmonary disease & $70(11.7)$ & $62(11.8)$ & $8(11.3)$ & .894 \\
\hline Malignancy & $104(17.5)$ & $98(18.7)$ & $6(8.6)$ & .036 \\
\hline Parkinson's disease & $16(2.7)$ & $9(1.7)$ & $7(9.9)$ & $<.001$ \\
\hline Arthritis/osteoarthrosis & $193(32.5)$ & $174(33.3)$ & $19(26.8)$ & .272 \\
\hline Dementia (MMSE < 19 points) & $98(16.4)$ & $59(11.2)$ & $34(46.6)$ & $<.001$ \\
\hline Good self-reported health (No., \%) & $418(69.8)$ & $379(72.1)$ & $37(61.7)$ & .133 \\
\hline \multicolumn{5}{|l|}{ Functional ability } \\
\hline Instrumental Activities of Daily Living (points, median, IQR) $\dagger$ & $18(12-27)$ & $16(12-24)$ & $35(33-36)$ & $<.001$ \\
\hline Physical activity score (points, median, IQR) $\ddagger$ & $7(4-8)$ & $7(5-9)$ & $4(4-6)$ & $<.001$ \\
\hline Gait speed (m/s, mean, SD) & NA & $0.52(0.2)$ & NA & - \\
\hline
\end{tabular}

men). Slow gait speed ( $\leq 0.40 \mathrm{~m} / \mathrm{s}$ in women and $\leq 0.45 \mathrm{~m} / \mathrm{s}$ in men) was associated with the highest HR for mortality (HR, 2.04; 95\% CI, 1.61-2.59; $P<.001$, model 1). Further adjustment for chronic diseases, body mass index, smoking, systolic blood pressure, self-reported health, Physical Activity Score, and walking aid use (model 2) attenuated results, as did additional adjustment for 15-item Geriatric Depression Scale and Mini Mental State Examination in model 3. Moderate gait speed was significantly associated with mortality (HR, 1.42; 95\% CI, 1.15-1.75; $P=.001$, model 1). The significant association between gait speed and mortality was lost after adjustment for Instrumental Activities of Daily Living (model 4) and in the fully adjusted model 6 (both, $P>$.080).

Figure 2C shows the Kaplan-Meier cumulative survival curve for all-cause mortality stratified for gender-specific tertiles of Instrumental Activities of Daily Living. After 5 years of follow-up, 27.6\% $(n=53)$ of the 192 participants with poor Instrumental Activities of Daily Living ability ( $\geq 25$ points in men and women) survived (Figure 2C). As shown in Table 2 (right), poor Instrumental Activities of Daily Living ability was associated with increased risk of mortality (HR, 2.75; 95\% CI, 2.22-3.40; $P<.001$, model 1). In the fully adjusted model (including gait speed), poor Instrumental Activities of Daily Living ability was still significantly associated with a higher mortality risk (HR, $1.70 ; 95 \%$ CI, 1.16-2.37; $P=.006)$. Moderate Instrumental Activities of Daily Living ability was not associated with increased mortality. Repeating the analysis in independently living community-dwelling participants did not change results significantly, as shown in Supplemental Table 1. The results for the 2-year mortality analysis are shown in Table 3. After 2 years of follow-up, $78.1 \%(n=136)$ of the 174 participants with the slowest walking speed survived compared with $90.3 \%(n=159)$ of those with the fastest gait speed. Slow gait speed was associated with a higher 2-year risk for mortality compared with the long-term follow-up analysis (HR, 2.66; 95\% CI, 1.49-1.74; $P=.001$, model 1). However, further adjustment for confounders attenuated results. After 2 years of follow-up, 

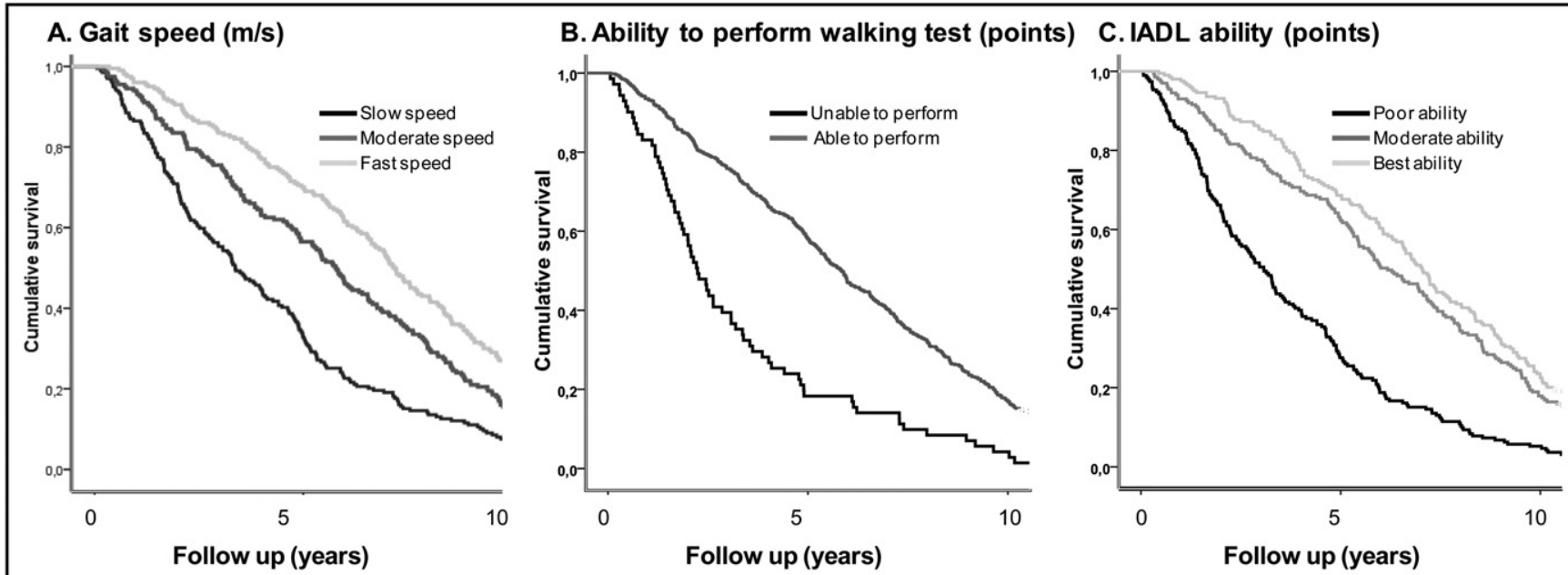

Alive $\mathrm{N}=599$

$\mathrm{N}=318$

$N=92$

Figure 2 Kaplan-Meier cumulative survival curves for all-cause mortality according to (A) gender-specific tertiles of gait speed, (B) ability to perform walking test, and (C) gender-specific tertiles of Instrumental Activities of Daily Living at age 85 years. $\mathrm{IADL}=$ Instrumental Activities of Daily Living.

$64.6 \%(\mathrm{n}=124)$ of the 192 participants with poor ability in Instrumental Activities of Daily Living survived compared with $93.1 \%(\mathrm{n}=190)$ of those with best ability in Instrumental Activities of Daily Living. Poor ability in Instrumental Activities of Daily Living was associated with a higher risk for mortality after 2 years compared with the long-term follow-up analysis (HR, 6.11; 95\% CI, 3.44-10.87; $P<.001$, model 1 ). In the fully adjusted model, Instrumental Activities of Daily Living were still significantly associated with a higher mortality risk (HR, 3.38 ; $95 \%$ CI, $1.47-7.80 ; P=.001)$. After 2 years, moderate ability in Instrumental Activities of Daily Living was also associated with increased mortality, but signif- icance was lost in the fully adjusted model (model 6, Table 3). Similar results were found regarding gait speed, Instrumental Activities of Daily Living, and 1-year mortality risk (Supplemental Table 2).

\section{DISCUSSION}

Faster gait speed was associated with improved survival in a cohort of oldest old people aged 85 years of the general population with a total follow-up of 12.2 years. Furthermore, our findings show that oldest old participants cutoff points of gait speed associated with higher risk of mortality are slower than $0.41 \mathrm{~m} / \mathrm{s}$ in women and $0.46 \mathrm{~m} / \mathrm{s}$ in men.

Table 2 Mortality Risk Stratified By Gender-Specific Tertiles of Gait Speed and Instrumental Activities of Daily Living at Age 85 Years in the Total Cohort

\begin{tabular}{|c|c|c|c|c|c|c|}
\hline & \multicolumn{3}{|c|}{ Gait Speed Tertile (m/s) N=526 } & \multicolumn{3}{|c|}{ GARS-IADL Tertile (Points) $N=599$} \\
\hline & $\begin{array}{l}\text { Slowest } \\
\text { HR }(95 \% \text { CI })\end{array}$ & $\begin{array}{l}\text { Moderate } \\
\text { HR }(95 \% \text { CI })\end{array}$ & $\begin{array}{l}\text { Fastest } \\
\text { HR }(95 \% \mathrm{CI})\end{array}$ & $\begin{array}{l}\text { Poor } \\
\text { HR }(95 \% \mathrm{CI})\end{array}$ & $\begin{array}{l}\text { Moderate } \\
\text { HR }(95 \% \text { CI })\end{array}$ & $\begin{array}{l}\text { Best } \\
\text { HR }(95 \% \mathrm{CI})\end{array}$ \\
\hline Model 1 & $2.04(1.61-2.59)$ & $1.42(1.15-1.75)$ & 1 (ref) & $2.75(2.22-3.40)$ & $1.19(0.96-1.47)$ & 1 (ref) \\
\hline Model 2 & $1.44(1.05-1.97)$ & $1.29(1.02-1.64)$ & 1 (ref) & $1.91(1.41-2.59)$ & $1.08(0.85-1.36)$ & 1 (ref) \\
\hline Model 3 & $1.26(0.89-1.79)$ & $1.27(0.99-1.69)$ & 1 (ref) & $1.69(1.19-2.40)$ & $1.06(0.83-1.35)$ & 1 (ref) \\
\hline Model 6 & $1.12(0.78-1.61)$ & $1.22(0.95-1.56)$ & 1 (ref) & $1.70(1.16-2.37)$ & $1.03(0.80-1.33)$ & 1 (ref) \\
\hline
\end{tabular}


Table 3 Two-Year Mortality Risk $(n=114)$ Stratified by Gender-Specific Tertiles of Gait Speed and Instrumental Activities of Daily Living at Age 85 Years in the Total Cohort

\begin{tabular}{|c|c|c|c|c|c|c|}
\hline & \multicolumn{3}{|c|}{ Gait Speed Tertile $(\mathrm{m} / \mathrm{s}) \mathrm{N}=526$} & \multicolumn{3}{|c|}{ GARS-IADL Tertile (Points) N $=599$} \\
\hline & $\begin{array}{l}\text { Slowest } \\
\text { HR }(95 \% \text { CI })\end{array}$ & $\begin{array}{l}\text { Moderate } \\
\text { HR }(95 \% \text { CI })\end{array}$ & $\begin{array}{l}\text { Fastest } \\
\text { HR }(95 \% \text { CI })\end{array}$ & $\begin{array}{l}\text { Poor } \\
\text { HR }(95 \% \text { CI })\end{array}$ & $\begin{array}{l}\text { Moderate } \\
\text { HR }(95 \% \text { CI })\end{array}$ & $\begin{array}{l}\text { Best } \\
\text { HR (95\% CI) }\end{array}$ \\
\hline Model 1 & $2.66(1.49-4.75)$ & $1.74(0.94-3.23)$ & 1 (ref) & $6.11(3.44-10.87)$ & $2.35(1.25-4.42)$ & 1 (ref) \\
\hline Model 2 & $1.79(0.88-3.61)$ & $1.40(0.72-2.72)$ & 1 (ref) & $4.12(2.00-8.46)$ & $2.25(1.16-4.34)$ & 1 (ref) \\
\hline Model 3 & $1.84(0.84-4.04)$ & $0.74(0.83-3.36)$ & 1 (ref) & $4.02(1.78-8.99)$ & $2.25(1.14-4.44)$ & 1 (ref) \\
\hline Model 4 & $1.23(0.59-2.60)$ & $1.29(0.66-2.50)$ & 1 (ref) & - & - & \\
\hline Model 5 & - & - & & $3.49(1.64-7.43)$ & $2.00(1.02-3.95)$ & 1 (ref) \\
\hline Model 6 & $1.42(0.64-3.18)$ & $1.52(0.76-3.18)$ & 1 (ref) & $3.38(1.47-7.80)$ & $1.91(0.94-3.58)$ & 1 (ref) \\
\hline
\end{tabular}

Also, inability to perform the walking test was associated with increased risk of mortality. Instrumental Activities of Daily Living disability was highly predictive for poor survival in oldest old people after short-term and long-term follow-up. This association was independent of common confounders and gait speed, and remained strong after selection of only community-dwelling participants.

Our findings showed that in oldest old people, slow gait speed was associated with an increased risk of poor survival compared with fastest gait speed in short-term and longterm follow-up. However, after adjustment for common confounders this association was lost. In particular, the Mini Mental State Examination was an important confounder in the association between walking speed and survival. This finding is in line with earlier studies reporting on positive association between slow walking speed and future cognitive decline. ${ }^{2}$ Also, applying earlier reported cutoff points for gait speed ${ }^{2,3}$ of $0.8 \mathrm{~m} / \mathrm{s}$ and $1.0 \mathrm{~m} / \mathrm{s}$ in patients able to complete the walking test identified 478 participants (91\%) at increased risk of adverse outcome and 516 participants $(98 \%)$ at higher risk of mortality. However, our results showed that after 5 years of follow-up, $72.1 \%(n=127)$ of the 176 participants in the fastest gait speed tertile $(\geq 0.59$ $\mathrm{ms}$ in women and $\geq 0.69 \mathrm{~ms}$ in men) survived. This result is in contrast to the finding of Studenski et $\mathrm{al}^{3}$ that walking speed slower than $0.8 \mathrm{~m} / \mathrm{s}$ was associated with a 5 -year survival of $49 \%$ in people aged 85 years or more. This may be in part explained by the fact that the mean age of all participants in that study was approximately 10 years younger than in our population, although 1765 participants were aged over 85 years, which represented $5 \%$ of the total study population. In addition, we have included cognitive impairment and depressive symptoms as confounders. However, in clinical practice gait speed can still serve as a single summary marker of net risk in oldest old Western populations and individuals. To illustrate the differences in walking speed for the clinician, we calculated the time it would take to walk $6 \mathrm{~m}$, for example, from a waiting room to the doctor's office. With a speed of $0.8 \mathrm{~m} / \mathrm{s}$, it would take 7.5 seconds to walk this distance. A fast-walking 85 -yearold man takes a maximum of 8.6 seconds $(0.69 \mathrm{~m} / \mathrm{s})$ and a fast-walking 85 -year-old woman takes a maximum of 10.2 seconds $(0.59 \mathrm{~m} / \mathrm{s})$ to walk $6 \mathrm{~m}$. In contrast, slow-walking 85 -year-old men $(0.45 \mathrm{~m} / \mathrm{s})$ and women $(0.40 \mathrm{~m} / \mathrm{s})$ take a minimum of 13 and 15 seconds, respectively, to walk $6 \mathrm{~m}$.

In clinical practice, we expect a larger proportion of oldest old patients to be unable to perform a walking test because of functional limitation and cognitive impairment. We have shown that inability to perform the walking test is a predictor of adverse outcome in itself. In case of inability to walk, assessment of Instrumental Activities of Daily Living disability, which is already part of the geriatric assessment, could be a good alternative to predict survival. Instrumental Activities of Daily Living disability can also be assessed with the aid of guardian. Also, Instrumental Activities of Daily Living disability can be used as a tool if conditions in the clinic render a walking test not feasible.

We found that assessment of Instrumental Activities of Daily Living ability by use of questionnaire was a strong predictor of survival in oldest old after adjustment for common confounders, in particular with regard to 2-year mortality. After 5 years of follow-up, only $27.6 \%$ of the participants with poor ability in Instrumental Activities of Daily Living ( $\geq 25$ points in men and women) survived (Figure 2C). An important feature of the Groningen Activity Restriction Scale questionnaire measuring Instrumental Activities of Daily Living dependency is that it does not assess actual performance, but competence. ${ }^{14}$ By measuring actual competence it attenuates the influence of social roles, for example, as seen in men. Earlier reports have shown that self-reported abilities are predictive of future function, health, and mortality in different populations and are com- 
parable to performance-based measures. ${ }^{9-11,18}$ Our finding supports an earlier study that reported that performancebased functional ability had no added value in predicting survival if disability in activities of daily living were present in older people. ${ }^{18}$

The strengths of this study are related to its design. The Leiden 85-plus Study is a unique longitudinal populationbased cohort study of 599 oldest old people with extensive measures for health and functioning with a follow-up of up to 12 years. Therefore, the results can be generalized to the western population of oldest old. Furthermore, our study enabled us to analyze in subpopulations with different characteristics. A limitation is that associations were tested in a cohort of the general population and not in a clinical population of oldest old people, but it is likely that the associations would be even stronger in a frailer population of elderly. Also, gait speed was not measured at usual speed from a standing position, but participants were instructed to walk as fast as possible. Finally, gait speed and Instrumental Activities of Daily Living were measured at baseline at age 85 years. We cannot exclude that decline in gait speed or ability in Instrumental Activities of Daily Living during follow-up is an even better predictor of adverse outcome. If this is the case, multiple measurements by a clinician might have an added value.

\section{CONCLUSIONS}

Gait speed in oldest old people is a useful tool to assess survival prognosis. However, the cutoff points of gait speed in oldest old people need to be reevaluated. Inability to perform a walking test is a marker of adverse outcome. Assessment of Instrumental Activities of Daily Living by questionnaire might be a better tool for prognostication in the oldest old population. This is supported by our finding that poor ability in Instrumental Activities of Daily Living was associated with a significantly higher 2-year mortality risk. Our findings contribute to the body of knowledge about the growing segment of the oldest old people and emphasize the need for further studies to find the best suitable prognostic markers for survival in oldest old people.

\section{References}

1. Cesari M. Role of gait speed in the assessment of older patients. JAMA. 2011;305:93-94.
2. Abellan van Kan G, Rolland Y, Andrieu S, et al. Gait speed at usual pace as a predictor of adverse outcomes in community-dwelling older people an International Academy on Nutrition and Aging (IANA) Task Force. J Nutr Health Aging. 2009;13:881-889.

3. Studenski S, Perera S, Patel K, et al. Gait speed and survival in older adults. JAMA. 2011;305:50-58.

4. Hajjar I, Quach L, Yang F, et al. Hypertension, white matter hyperintensities, and concurrent impairments in mobility, cognition, and mood: the Cardiovascular Health Study. Circulation. 2011;123:858865.

5. Schrack JA, Simonsick EM, Ferrucci L. The energetic pathway to mobility loss: an emerging new framework for longitudinal studies on aging. J Am Geriatr Soc. 2010;58:S239-S336.

6. Sona A, Maggiani G, Astengo M, et al. Determinants of recourse to hospital treatment in the elderly. Eur J Public Health. 2012;22:76-80.

7. Active Ageing. A Policy Framework. Geneva: World Health Organization; 2002 (document WHO/NMH/NPH/02.8).

8. Cesari M, Onder G, Zamboni V, et al. Physical function and self-rated health status as predictors of mortality: results from longitudinal analysis in the ilSIRENTE study. BMC Geriatr. 2008;8:34.

9. Reuben DB, Siu AL, Kimpau S. The predictive validity of self-report and performance-based measures of function and health. $J$ Gerontol. 1992;47:M106-110.

10. Hoeymans N, Feskens EJ, van den Bos GA, et al. Measuring functional status: cross-sectional and longitudinal associations between performance and self-report (Zutphen Elderly Study 1990-1993). J Clin Epidemiol. 1996;49:1103-1110.

11. Latham NK, Mehta V, Nguyen AM, et al. Performance-based or self-report measures of physical function: which should be used in clinical trials of hip fracture patients? Arch Phys Med Rehabil. 2008; 89:2146-2155.

12. Bootsma-van der Wiel A, van Exel E, de Craen AJM, et al. A high response is not essential to prevent selection bias: results from the Leiden 85-plus Study. J Clin Epidemiol. 2002;55:1119-1125.

13. Bootsma-van der Wiel A, Gussekloo J, De Craen AJ, et al. Common chronic diseases and general impairments as determinants of walking disability in the oldest-old population. J Am Geriatr Soc. 2002;50: 1405-1410.

14. Kempen GI, Miedema I, Ormel J, Molenaar W. The assessment of disability with the Groningen Activity Restriction Scale. Conceptual framework and psychometric properties. Soc Sci Med. 1996;43:16011610.

15. Yesavage JA, Brink TL, Rose TL, et al. Development and validation of a geriatric depression screening scale: a preliminary report. $J$ Psychiatr Res. 1982;17:37-49.

16. Folstein MF, Folstein SE, McHugh PR. "Mini Psychological State". A practical method for grading the cognitive state of patients for the clinician. J Psychiatr Res. 1975;12:189-198.

17. van Eijk L. Activity and Well-being in the Elderly [thesis]. The Netherlands: University of Groningen; 1997.

18. Reuben DB, Seeman TE, Keeler E, et al. Refining the categorization of physical functional status: the added value of combining self-reported and performance-based measures. J Gerontol A Biol Sci Med Sci. 2004;59:1056-1061. 
Supplemental Table 1 Mortality Risk Stratified by Gender-Specific Tertiles of Gait Speed and Instrumental Activities of Daily Living at Age 85 Years in Independently Living Participants

\begin{tabular}{|c|c|c|c|c|c|c|}
\hline & \multicolumn{3}{|c|}{ Gait Speed Tertile $(\mathrm{m} / \mathrm{s}) \mathrm{N}=314$} & \multicolumn{3}{|c|}{ GARS-IADL Tertile (Points) $N=329$} \\
\hline & $\begin{array}{l}\text { Slowest } \\
\text { HR }(95 \% \text { CI })\end{array}$ & $\begin{array}{l}\text { Moderate } \\
\text { HR }(95 \% \text { CI })\end{array}$ & $\begin{array}{l}\text { Fastest } \\
\text { HR ( } 95 \% \text { CI) }\end{array}$ & $\begin{array}{l}\text { Poor } \\
\text { HR }(95 \% \text { CI) }\end{array}$ & $\begin{array}{l}\text { Moderate } \\
\text { HR }(95 \% \text { CI })\end{array}$ & $\begin{array}{l}\text { Best } \\
\text { HR }(95 \% \text { CI })\end{array}$ \\
\hline del 1 & $0(1.13-2.02)$ & $1.36(1.02-1.81)$ & 1 & $2.66(1.96$ & $1.11(0.86-1.45)$ & 1 (ref) \\
\hline odel 2 & 5) & 1 & 1 & ) & 0.97( & f) \\
\hline odel 3 & $0.99(0.68-1.46)$ & 1.23 & 1 & 1.73 & 0.95 & 1 (ref) \\
\hline odel 4 & $0.96(0.65-1.42)$ & $1.11(0.81-1$ & 1 (ref) & - & - & \\
\hline odel 5 & - & - & & $2.12(1.3$ & 0.97( & 1 (ref) \\
\hline Model 6 & $0.91(0.61-1.37)$ & $1.18(0.86-1.63)$ & 1 (ref) & $1.76(1.10-2.89)$ & $0.96(0.70-1.32)$ & 1 (ref) \\
\hline \multicolumn{7}{|c|}{$\begin{array}{l}\text { CI }=\text { confidence interval; HR }=\text { hazard ratio; GARS-IADL }=\text { Groningen Activity Restriction Scale Instrumental Activities of Daily Living. } \\
\text { Gait speed tertiles: women: slowest } 0.08-0.40 \mathrm{~m} / \mathrm{s} \text {, middle } 0.41-0.58 \mathrm{~m} / \mathrm{s} \text {, fastest } 0.59-1.12 \mathrm{~m} / \mathrm{s} ; \text { men: slowest } 0.13-0.45 \mathrm{~m} / \mathrm{s} \text {, middle } 0.46-0.68 \mathrm{~m} / \mathrm{s} \text {, } \\
\text { astest } 0.69-1.44 \mathrm{~m} / \mathrm{s} \text {. IADL tertiles: women: poor } 36-25 \text { points, moderate } 24-15 \text { points, best } 14-9 \text { points; men: poor } 36-25 \text { points; moderate } 23-14 \text { points, } \\
\text { pest } 13-9 \text { points. Model } 1 \text { is crude; model } 2 \text { is adjusted for summed score chronic diseases, systolic blood pressure, body mass index, smoking status, } \\
\text { elf-reported health, physical activity score, and walking aid use; model } 3 \text { is adjusted as model } 2 \text {, Geriatric Depression Scale, and Mini Mental State } \\
\text { xamination; model } 4 \text { is adjusted as model } 2 \text { and IADL (for gait speed analysis); model } 5 \text { is adjusted as model } 2 \text { and gait speed (for IADL analysis); model } \\
\text { is adjusted for all included variables. }\end{array}$} \\
\hline
\end{tabular}

Supplementary Table 2 One-Year Mortality Risk $(n=47)$ Stratified by Gender-Specific Tertiles of Gait Speed and Instrumental Activities of Daily Living at Age 85 Years in the Total Cohort

\begin{tabular}{|c|c|c|c|c|c|c|}
\hline & \multicolumn{3}{|c|}{ Gait Speed Tertile (m/s) N=526 } & \multicolumn{3}{|c|}{ GARS-IADL Tertile (Points) $N=599$} \\
\hline & $\begin{array}{l}\text { Slowest } \\
\text { HR }(95 \% \text { CI })\end{array}$ & $\begin{array}{l}\text { Moderate } \\
\text { HR }(95 \% \text { CI })\end{array}$ & $\begin{array}{l}\text { Fastest } \\
\text { HR }(95 \% \mathrm{CI})\end{array}$ & $\begin{array}{l}\text { Poor } \\
\text { HR }(95 \% \text { CI })\end{array}$ & $\begin{array}{l}\text { Moderate } \\
\text { HR }(95 \% \text { CI })\end{array}$ & $\begin{array}{l}\text { Best } \\
\text { HR }(95 \% \mathrm{CI})\end{array}$ \\
\hline Model 1 & $2.70(1.13-6.46)$ & $1.29(0.48-3.47)$ & 1 (ref) & $8.02(2.81-22.87)$ & $3.63(1.20-11.02)$ & 1 (ref) \\
\hline Model 2 & $1.40(0.48-4.10)$ & $0.82(0.27-2.51)$ & 1 (ref) & $3.77(1.12-12.70)$ & $2.70(0.84-8.69)$ & 1 (ref) \\
\hline Model 3 & $1.84(0.61-5.55)$ & $0.74(0.23-2.38)$ & 1 (ref) & $5.62(1.49-21.22)$ & $2.54(0.77-8.34)$ & 1 (ref) \\
\hline Model 4 & $0.99(0.31-3.16)$ & $0.76(0.25-2.34)$ & 1 (ref) & - & - & \\
\hline Model 5 & - & - & & $3.54(0.96-1.30)$ & $2.59(0.78-8.65)$ & 1 (ref) \\
\hline Model 6 & $1.31(0.42-4.06)$ & $0.71(0.22-2.25)$ & 1 (ref) & $4.93(1.25-19.47)$ & $2.18(0.63-7.53)$ & 1 (ref) \\
\hline
\end{tabular}

